\title{
VIRTUAL PRODUCTION NETWORK CONFIGURATION: ACS-APPROACH AND TOOLS
}

\author{
Florian Golm*, Alexander V. Smirnov** \\ (*)FFA Ford Research Aachen, GERMANY \\ e-mail: fgolm@ford.com \\ (**) St.Petersburg Institute for Informatics and Automation \\ of the Russian Academy of Sciences, RUSSIA \\ e-mail: $\underline{\text { smir@mail.iias.spb.su }}$
}

\begin{abstract}
Interest in global businesses and such a new form of co-operation as Virtual Production Network (VPNet) is growing along with increasing use of Internetbased engineering and management technologies, and the trend towards VPNet data \& knowledge management. Affordable Cost Structure approach (ACS-approach) for VPNet configuration is a new approach to configuration of global production network in order to improve investment efficiency over total facility life-time. A kernel of this approach is a distributed multi-level constraint satisfaction technology based on a shared domain knowledge model "product-process - resources". The paper discusses a generic methodology and a research prototype of a distributed decision support system "ProCon" for VPNet configuration.
\end{abstract}

\section{INTRODUCTION}

The ability of a production system to be reconfigured as custom-orders change is closely related to the type of technological process/production resource selected and the arrangement of equipment on an enterprise network. In order to create a Virtual Production Network (VPNet) that can be reconfigured to meet the changing production demand, one has to understand the relationship between the structure of products and the structure of a VPNet. Applying Distributed Multi-Level Configuring in the context of inter-enterprises global and local (region-oriented) business collaboration within the Virtual Enterprise is named Virtual Production Network (or VPNet) Configuration.

A VPNet can be defined as a flexible connection of appropriate production modules at different locations with the target to fulfil a concrete production task, the production of a product in a determined volume, cost frame and time. The consortium exists for a predefined period of time. The production network becomes real when a concrete realization takes place or at least the necessary budget is endorsed. During the planning phase until the offer is ratified the VPNet represents a planning product in order to design and evaluate potential scenario solutions for the production task. Figure 1 explains roughly the basic concept of the virtual production network, a concept that Ford Motor Company may realize in the area of manual 
transmission with the target to coordinate and harmonize global production activities in a virtual distributed consortium of manufacturing plants (Golm, 1999).

The term VPNet has its origin in the concept of virtual enterprises (Eversheim, 1996;. Hirsch, 1995; IMTR, 1999; Gulledge, 1998; NIST, 1999; Preiss, 1996; Smirnov, 1999-a; Wildemann, 1996). The ACS-approach is similar but it refers to the coordination of production facilities in one company, in this case the Ford Motor Company. Nevertheless the integration of external companies as suppliers for production modules or tasks is principally possible. It is chiefly a horizontal structure, which means that the involved plants are having equal rights and responsibilities. Legal and formal circumstances are of minor relevance - these are rather the focus of virtual enterprise constellations.

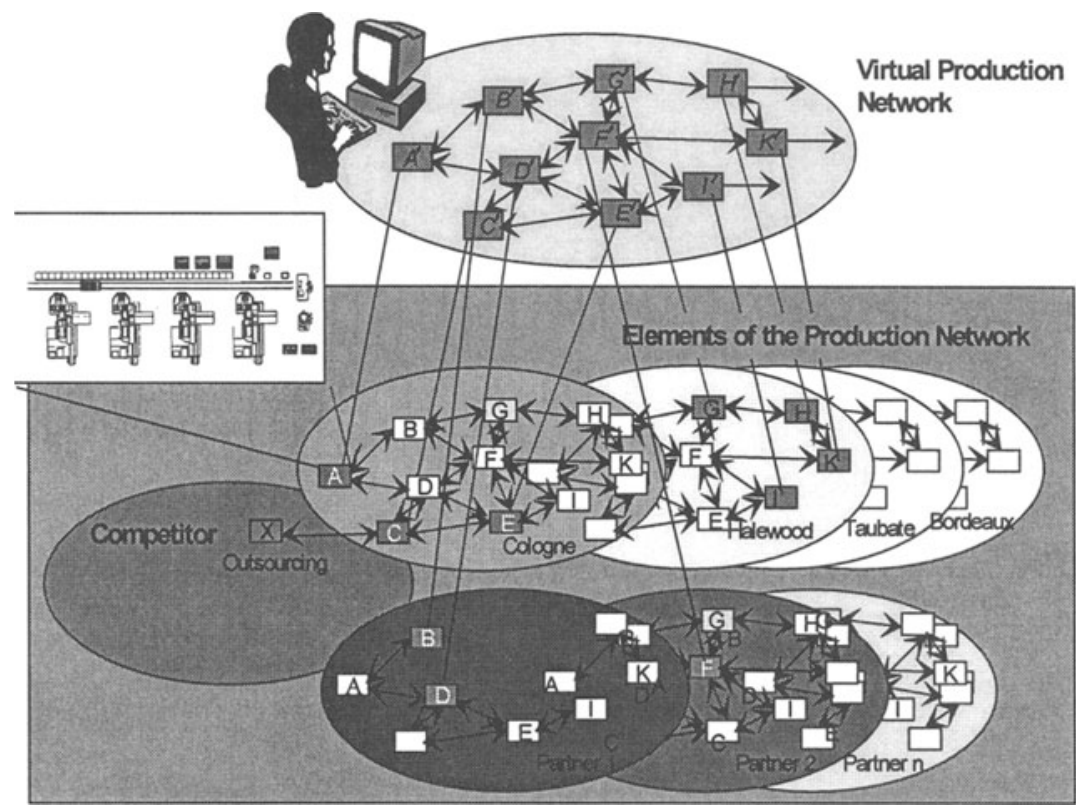

Figure 1 - Distributed multi-level configuring of virtual production network

Configuring as one of resource management technologies (that based on business processes reengineering approach) helps to keep legacy applications in business by transforming their current architecture to a new, more maintainable one. This approach is the discipline of identifying the configuration of a system at discrete points in time for the purpose of systematically controlled changes to the configuration and maintaining the integrity of the configuration throughout the system life cycle. The entity "Configuration" include the following parts: a baseline, a set of changes and a sequence of changes (Smirnov, 1996).

General objectives of this paper are to discuss a generic methodology and an architecture of distributed decision support system (DSS) for ACS-based resource management in VPNet, and also a local DSS on the level of production modules configuring. 


\section{ACS-APPROACH AND "ProCon"-TOOL STRUCTURE}

Current situation in global production planning is following:

- Partially free capacities in product dedicated plants;

- Insufficient shared funding for cross program projects;

- Cycle Plan instability prevents effective long term planning (shifting production volumes);

- Information deficits in central planning area;

- Insufficient holistic approach to optimize the entire production network.

In the area of manual transmissions, Ford owns four production plants, distributed in Europe and Brazil. The production network consists of the different plants respectively their production modules, which represent the general production potentials in a structured and more detailed way. Production modules are capable of producing parts or sub components or at least sub sequences of the entire production process. In the new concept a central planning staff is responsible for the coordination of production engineering and investment activities in order to fulfil new requirements for new manufacturing tasks. Reasons for the necessity to change the production system can be seen in shifting production volumes (Figure 2) of existing products or in the innovation of technologies or products in order to react on changing market situations or customer requirements.

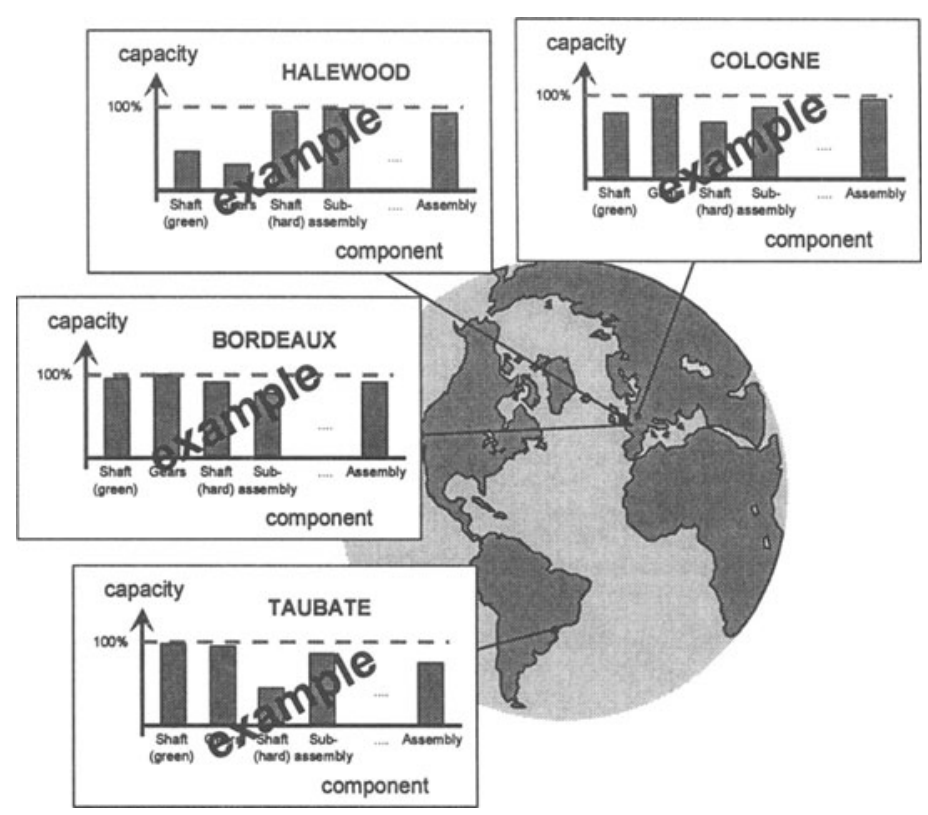

Figure 2 - Balancing of Production Capacities

In order to create a VPNet that can be reconfigured to meet the changing production demands, one has to understand the structure of the system "product business process - resources" (Smirnov, 1994). VPNet configuration generates 
customised solutions based on a standard components (as product baselines, technological process templates, and etc.) or VPNet model. Configuration consists of two aspects - configuring/reconfiguring and configuration maintenance. Configuring deals with creating configuration solutions; it involves selecting components and the manner of their configuring. Configuration maintenance deals with maintaining a consistent configuration under change; this requires the consistency among the selected components and decisions. When a decision for selected components changes, configuration maintenance must trace all the decisions related to the changed decision and revise them, if necessary, to maintain consistency among the components and decisions.

The configuring process incorporates the following features: order-free selection, limits of resources, optimization (minimization or maximization), default values, freedom to make changes in VPNet' Module model. Applying distributed configuring approach enables the formation of the VPNet concept model of the system "VPNet product - VPNet process - VPNet resource" satisfying the constraints on multi-level facilities/resources. The VPNet configuring stage is represented by relation "configuring of the product (product structure, materials bill) -> configuring of the business process (process structure, operation types) -> configuring of the resource (structure of system, equipment and staff types)" (Smirnov, 1994; Young, 1992s). The constraints satisfaction model has been applied to a wide range of VPNet problems (see Figure 3).

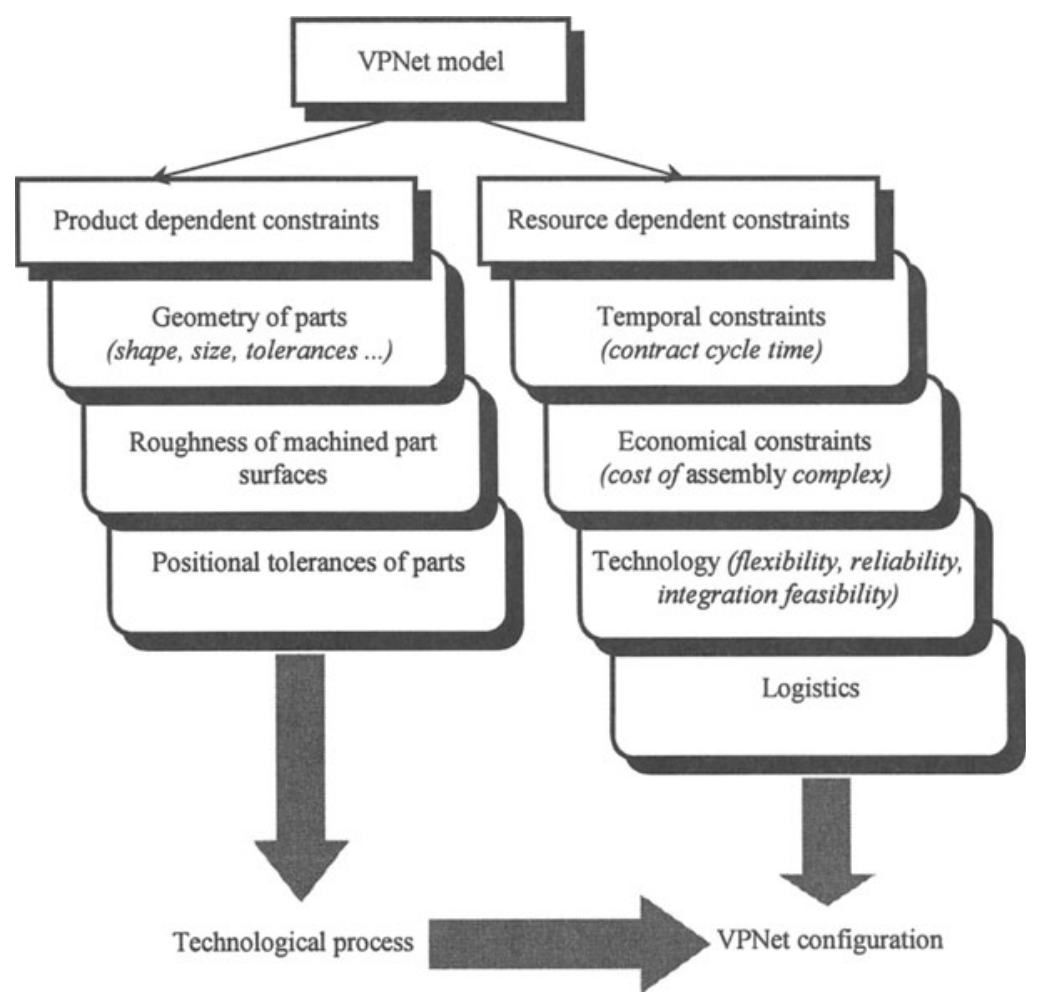

Figure 4 - Structure of VPNet model as "product-process-resource" model 
The conceptual model of the product structure is hierarchical. Such model as STEP advocates a hierarchical approach to product description. The STEP model divides the product into four levels: product, product version, subassembly, and part. The conceptual models of VPNet as manufacturing systems are also hierarchical (ISO TC 184/SC 5/WG 1, 1997). Such models as CAMT-I and NIST advocate a hierarchical approach to manufacturing system design and analysis (Nadoli, 1993). Our VPNet model (see Figure 4) divides the resource management system into five levels: location (plant), module (process facilities or real), line (production line), machine, and resource (cost centre). This approach was realised in Ford's project "Configuration and Optimization of Global Production Networks in Order to Improve Investment Efficiency over Total Facility Life-Time" (short title "Affordable Cost Structure" or ACS-approach). The general objective of the project was the development of a methodology and a software tool for selection and reuse of facilities; investment calculation on life cycle level and configuration of global production network, taking into account quantitative and qualitative aspects in cross program planning.

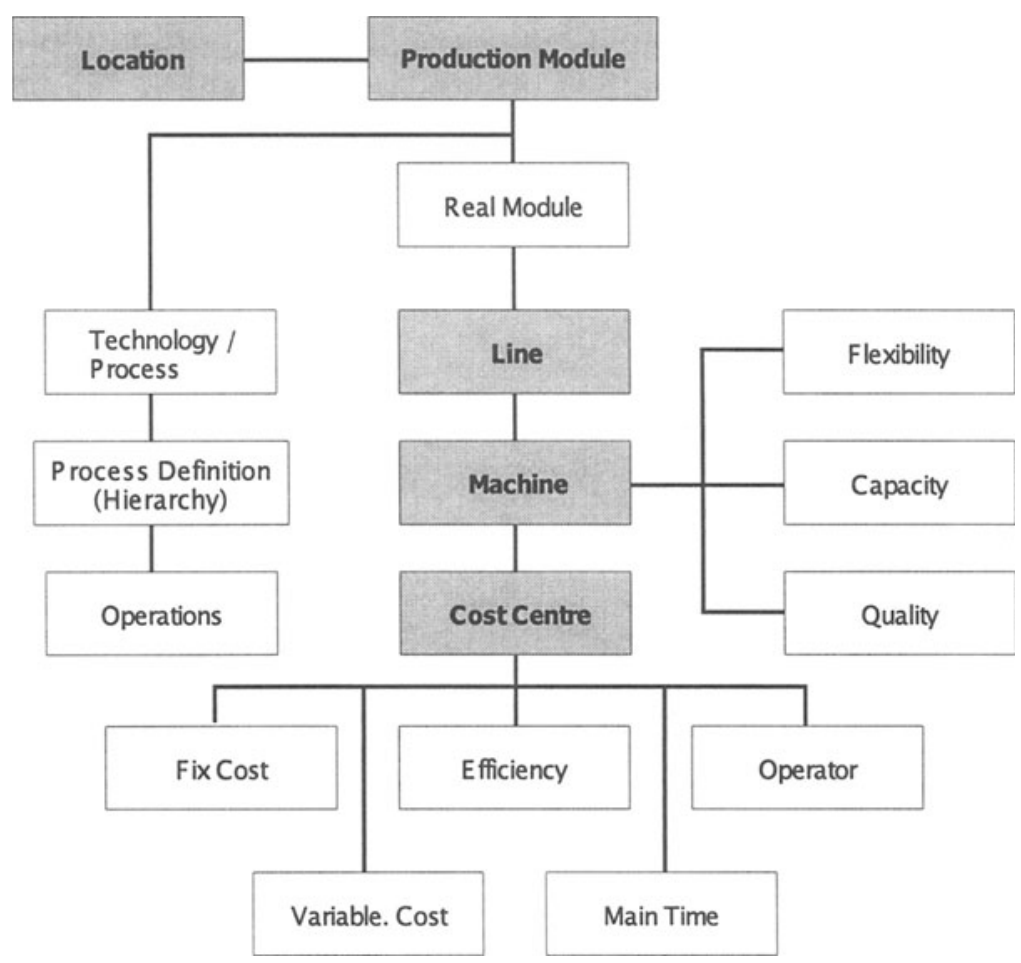

Figure 4 - Fragment of VPNet model hierarchy

DSS "ProCon" (Production network Configuration tool set) system was developed as one of results of the project. "ProCon" focuses on the early stages of planning procedure of investment calculation and determination for the (a) 
derivation of production scenarios, (b) determination of investment cost, (c) assignment of locations and (d) estimation of product variable cost.

The architecture of ProCon reflects the structure of VPNet concept. ProCon includes three main IT-Modules or software tools (see Figure 5). IT-Module 1 (Request definition): functions are: analysis of future capacity gaps, statistical analysis of production volumes, definition of requests, and provision of process standards. ITModule 2 (Offer processing) functions are: capacities balancing of requested modules, planning of necessary investments, and calculation of production and investment cost. IT-Module 3 (Order release): configuration of possible scenarios, evaluation of production networks, and consideration of logistic costs, taxes, local content, etc.

The roles of the project partners were distributed between following problem groups:

- Project co-ordination problems (the coordinator - FFA Ford Research Aachen, Germany): (1) project marketing, (2) conception, (3) analysis / definition of the problem.

- Research problems (the partners - WZL RWTH Aachen and Fraunhofer Institute for Production Technologies, Germany; St.Petersburg Institute for Informatics and Automation of Russian Academy of Sciences (SPIIRAS), Russia; North Caroline State University, USA): (1) analysis of the present situation, (2) methodical and conceptual work, (3) determining of the DSS structure, (4) realization of DSS prototype.

- Application problems (Ford Manual Transmission, Germany): (1) field of analysis, (2) discussion partner, (3) pilot user.

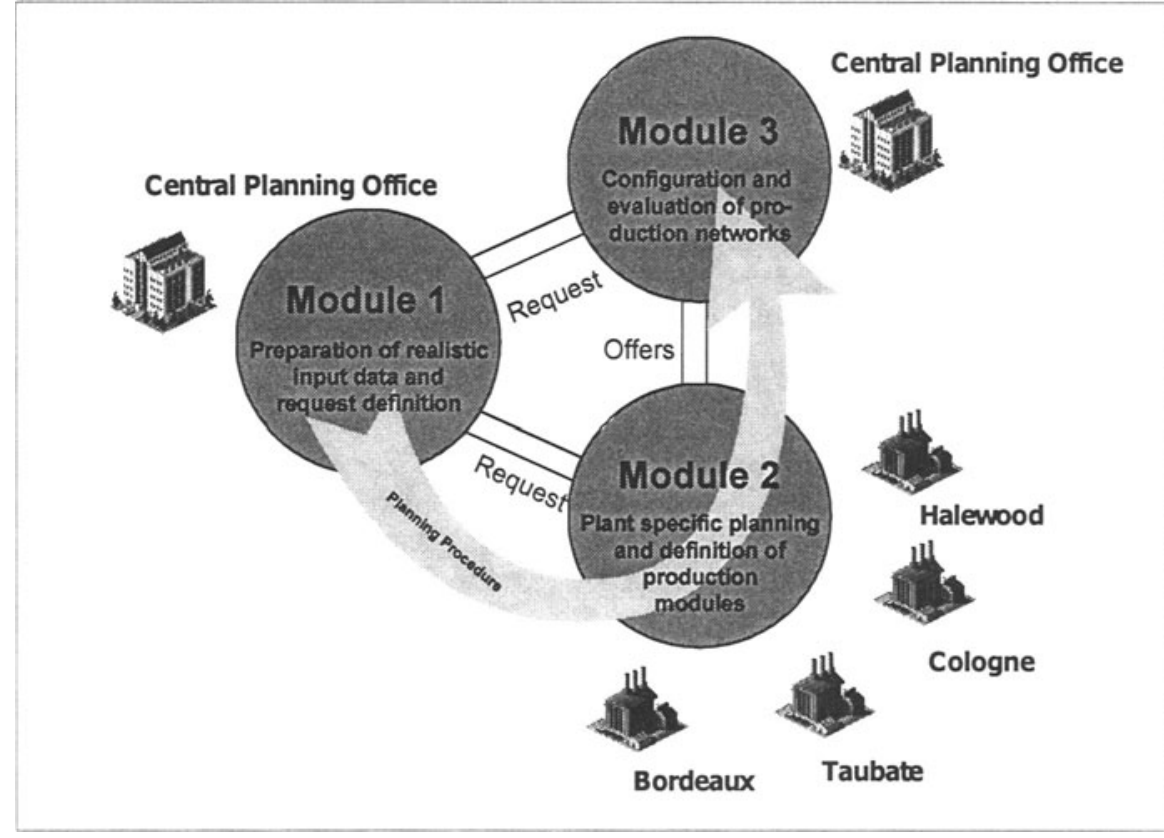

Figure 5 - ProCon structure 
In this paper the focus lays on IT-Module 2. This module concentrates on the view of the different plants that have to make offers in regards to the requested production modules. Therefore plant-specific know-how and data has to be maintained in this tool. In case of new requests handed over from IT-Module 1 decentral planners have to configure production modules and if needed select new facilities or machines supplementing existing ones. The generated data is given to a common database consisting of product cost, quality, flexibility, lead time for different products, productions modules and over different planning periods.

As the main kind of activity of most VPNet' unit (location) managers is the number of problems concerning a module configuring so the IT-Module 2 (or a local DSS) was based on the main stages of module configuration reengineering, namely:

1) Analysis of existing technological process;

2) Development of the new (future) technological process structure from re-usable solutions (operations);

3) Offer calculation;

4) Information support for the decision making process (configuration maintenance).

Main boundary conditions of offer calculation were:

1. Estimation of efforts for necessary logistics (transports, conservation before shipping etc.): (i) investments for machines, transportation utilities etc., (ii) variable cost;

2. Production modules were defined according to technological independence (as virtual modules when every virtual module was described using technological operation terms);

3. All data (cost, times, machinery, processes) were obtained from Ford plants in Cologne and Halewood;

\section{CONCLUSIONS}

The knowledge-based approach of „Affordable Cost Structure“ targets an efficient planning process on basis of virtual production networks according to cross program planning, reuse of resources, and more secure planning data.

Knowledge-based VPNet configuring technology is an innovative technology in the domain of global manufacturing and supply chain management. Using this technology enables people to make faster and better-quality decisions on GPN configurations from template solution (re-usable solution) under constraints networks with reduced variance. Implementation of this technology will be followed by increased quality, reduced cost, reduced errors, and etc..

First estimations of ProCon made in a case study have shown high economic and qualitative potential benefits for application of the ACS approach.

In the future the ACS-project could develop in the following directions:

1. Methodical verification and adaptation: analyze and modify as-is planning process, identify additional methodical needs, analyze and implement necessary data, educate people concerned (planning staff, plant engineers etc.).

2. Software Engineering: improve data structure and algorithms, adapt to Ford standards, implement links to existing software tools, improve ergonomics (GUI) and usability, coordination with running Ford SW-projects, network capability, training. 
3. Organization framework: implement to-be planning process; competence structure, people, processes; balance ACS-approach and organization; production module definition, adapt cost structure; data / information acquisition, preparation, maintenance.

\section{REFERENCES}

1. Eversheim W, Franke R, Kalkert W, Schuh G. u.a. "Kooperative Wertschðpfung - Produkt, ProzeB, Ressourcen Wettbeweerbsfaktor Produktionstechnik". In AWK '96 Proceedings. VDI-Verlag GmbH Dusseldorf, 1996

2. Hirsch B. Information System Concept for the Management of Distributed Production. Computers in Industry, Elsevier Science B.V., 1995, 26, pp. 229 - 241.

3. Technologies for Enterprise Integration, Rev 3.1 (Oct 99), Integrated Manufacturing Technology Roadmapping Project, Oak Ridge Centers for Manufacturing Technology, Oak Ridge, Tennessee.(URL: HTTP://TMTI21.ORG)

4. ISO TC 184/SC 5/WG 1, 1997 "Requirements for enterprise reference architectures and methodologies" http://www.mel.nist.gov/sc5wg1/gera-std/ger-anxs.html]

5. Golm F. "Planung globaler Produktionsnetzwerke". In Proceedings of Deutscher Logistik Congress, Berlin, Oc tober 1999

6. Gulledge TR, Sommer RA. "Aligning strategic objectives with organizational processes: a methodology for virtual enterprise implementation". In Proceedings of the International Confernece of the Manufacturing Value Chain . August '98, Troon, Scotland, Kluwer Academic Publishers, 1998

7. Nadoli G., Biegel L. Intelligent manufacturing-Simulation Agent Tool (IMSAT). ACM Transactions on Modeling and Computer Simulation, vol.3, N 1, 1993, pp. 42-65.

8. NIST: Manufacturing Enterprise Integration Program (November, 1999), National Institute of Standards and Technology, Gaithersburg, Maryland. (URL: HTTP://WWW.ATP.NIST.GOV)

9. Preiss K, Goldman SL, Nagel RN. Cooperate to Compete - Building Agile Business Relationships, Van Nostrand Reinhold, 1996.

10. Smirnov A. "Virtual Enterprise Configuration Management". In Proceedings of the $14^{\text {th }}$ IFAC World Congress (IFAC'99), Beijing, China, Pergamon Press, vol. A, July 1999, pp.337-342.

11. Smirnov AV, Sheremetov LB. Component Integration Framework for Manufacturing Systems Re-Engineering Based in Agents and Objects. International Journal of Robotics and Autonomous Systems, Elsevier, North-Holland, 27(1-2), 1999, pp.77-89.

12. Smirnov AV, Sheremetov LB. Configuration of Complex Systems Based on the Technology of Intelligent Agents. Automatic Control and Computer Sciences, Allerton Press, Inc., N.Y., Vol.32, No 4, .1998, pp. 15-24.

13. Smirnov A, Sheremetov L, Turbin P. "Information Support of FMS Configuration Design". In Balanced Automation Systems II - Implementation challenges for anthropocentric manufacturing (Camarinha-Matos, L.M., Afsarmanesh, H. (Eds.)): 2nd IEEE/ECLA/IFIP International Conference on Architectures and Design Methods for Balanced Automation Systems - BASYS'96, Chapman \& Hall, 1996, pp. 357-364.

14. Smirnov AV. "Conceptual Design for Manufacture in Concurrent Engineering". In Proceedings of the Conference "Concurrent Engineering: Research and Applications", Pittsburgh, Pennsylvania. 1994, pp.461-466.

15. Young RE, Greef A, O'Grady P. An Artificial Intelligence Constraint Network System for Concurrent Engineering, International Journal of Production Engineering, 1992, vol. 30, 7, pp. $1715-1735$. 